\title{
Untrivial Pursuit: Measuring Motor Procedures Learning in Children with Autism
}

\author{
Laura Sparaci, Domenico Formica, Francesca Romana Lasorsa, Luigi Mazzone, \\ Giovanni Valeri, and Stefano Vicari
}

\begin{abstract}
Numerous studies have underscored prevalence of motor impairments in children with autism spectrum disorders (ASD), but only few of them have analyzed motor strategies exploited by ASD children when learning a new motor procedure. To evaluate motor procedure learning and performance strategies in both ASD and typically developing (TD) children, we built a virtual pursuit rotor (VPR) task, requiring tracking a moving target on a computer screen using a digitalized pen and tablet. Procedural learning was measured as increased time on target (TT) across blocks of trials on the same day and consolidation was assessed after a 24-hour rest. The program and the experimental setting (evaluated in a first experiment considering two groups of TD children) allowed also measures of continuous time on target (CTT), distance from target (DT) and distance from path (DP), as well as 2D reconstructions of children's trajectories. Results showed that the VPR was harder for children with ASD than for TD controls matched for chronological age and intelligence quotient, but both groups displayed comparable motor procedure learning (i.e., similarly incremented their TT). However, closer analysis of CTT, DT, and DP as well as 2D trajectories, showed different motor performance strategies in ASD, highlighting difficulties in overall actions planning. Data underscore the need for deeper investigations of motor strategies exploited by children with ASD when learning a new motor procedure. Autism Res 2015, 8: 398-411. (C) 2015 International Society for Autism Research, Wiley Periodicals, Inc.
\end{abstract}

Keywords: procedural learning; autism; pursuit rotor; motor skills; handwriting

\section{Introduction}

A growing number of studies has progressively highlighted the importance of analyzing motor skills and their acquisition in children with autism spectrum disorders (ASD) [Bhat, Landa, \& Galloway, 2011; Fournier, Hass, Naik, Lodha, \& Cauraugh, 2010; Iverson \& Wozniack, 2007; Leonard et al., 2014; McCleery, Elliott, Sampanis, \& Stefanidou, 2013; Sparaci, Stefanini, D'Elia, Vicari, \& Rizzolatti, 2014; Vivanti et al., 2011]. However, only few studies have considered abnormalities in motor skills learning (as included in the broader construct of procedural learning), which may in turn have cascading affects on the acquisition of more complex motor abilities [Dziuk, Gidley Larson, Apostu, Mahone, Denckla, \& Mostofsky, 2007; Gidley Larson \& Mostofsky, 2008]. Furthermore, most research on motor skills in ASD has been based on clinical standardized tests, providing little or no details on underlying motor performance strategies [Gowen \& Hamilton, 2013]. In the present study, we attempted to tackle these issues by examining motor procedure learning in children with ASD, while evaluating differences in underlying performance strategies.

Procedural learning is implicit (i.e., learning to ride a bike or to tie a shoelace), proceeding through repeated exposure and practice of a task and resulting in knowledge that improves performance even when it is difficult to verbalize and/or visualize, and has often been said to be inflexible and unrelated to intelligence quotient (IQ). It is often described in contrast to declarative learning which is explicit (e.g., knowledge of facts, episodes, lists), as it can be brought to mind verbally (as a proposition) or nonverbally (as an image), and has often been described as flexible and strongly correlated to IQ [Brown, Aczel, Jimenez, Kaufman, \& Grant, 2010; Cohen \& Poldrack, 1997; Rosenbaum, 2010; Squire, 1986; Vicari, Verucci, \& Carlesimo, 2007]. Procedural learning is extremely important in child development, underling many social communicative skills, such as gesture acquisition [Capirci \& Volterra, 2008], language [Ullman, 2004], and handwriting skills [Volman, van Schendel, \&

From the Language and Communication Across Modalities Laboratory (LaCAM), Institute of Cognitive Sciences and Technologies (ISTC), Italian National Research Council (CNR), Via Nomentana 56, 00161 Rome, RM, Italy (L.S., F.R.L.); Laboratory of Biomedical Robotics and Biomicrosystems, (CIR), University Campus Biomedico, Rome, RM, Italy (D.F); Division of Child and Adolescent Psychiatry, Bambino Gesù Children's Hospital, IRCCS, Piazza Sant'Onofrio 4, 00165, Rome, RM, Italy (L.M., G.V., S.V.)

Received July 23, 2014; accepted for publication November 25, 2014

Address for correspondence and reprints: Laura Sparaci, Institute of Cognitive Sciences and Technologies, Via Nomentana 56, 00161 Rome, Italy. E-mail: laura.sparaci@istc.cnr.it

Published online 30 January 2015 in Wiley Online Library (wileyonlinelibrary.com)

DOI: $10.1002 /$ aur. 1455

(C) 2015 International Society for Autism Research, Wiley Periodicals, Inc. 
Jongmans, 2006]. Most tasks engage both procedural and declarative learning, but some paradigmatic tasks have been specifically designed to assess procedural learning. In particular, pursuit rotor (PR) tasks have been used from the mid-50s to test motor procedure learning in both typical and atypical adult and child populations [Ammons, Alprin, \& Ammons, 1955; Davol \& Breakell, 1965; Dunham, Allan, \& Winter, 1985; Gabay, Schiff, \& Vakil, 2012; Grafton, Mazziotta, Presty, Friston, Franckowiak, \& Phelpsis, 1992; Grafton, Woods, \& Tyska, 1994; Horn, 1975; Harrington, Haaland, Yoe, \& Marder, 1990; Hatakenaka, Miyai, Mihara, Yagura, \& Hattori, 2012; Hsu \& Bishop, 2014; Lord \& Hulme, 1988; Sarazin, Deweer, Merkl, Poser, Pillon, \& Dubois, 2002; Schmidtke, Manner, Kaufmann, \& Schmolck, 2002]. Traditional PR tasks require participants to manually track a moving target presented on a turntable using a handheld stylus, by keeping the tip of the stylus on a metal spot on the platter. Changes in task design (i.e., target speed or track shape) have been used to evaluate development of procedural learning in children [Eckert, 1974; Frith, 1968; Karlin, 1965; Mounoud, Viviani, Hauert, \& Guyon, 1985; Whitehurst \& Del Rey, 1983; Zanone, 1990].

A critique to initial studies using the PR task was that while producing a large amount of data on differences in children's performance levels, motives of these differences were hardly ever investigated [Frith, 1973]. A mayor limitation was due to measuring only participants overall time on target (TT), rarely considering that similar overall TT could arise from very different motor strategies [Frith \& Frith, 1974]. For example, to achieve smooth tracking participants in a PR task must pass from feedback-based strategies (i.e., relying on visual and/or kinesthetic information to detect the target's position and then make appropriate adjustments) to feedforward-based strategies (i.e., building a forward model and anticipating the target's position) [Frith, 1973; von Hofsten \& Rosander, 1997]. However, similar TT scores could arise using both motor strategies [Frith, 1971]. Furthermore, TT cannot provide any information about what the participant is doing when he/she is off target. For example, participants in drawing tasks may be able to get into the rhythm of the task quite well, but may be continually slightly behind or slightly in front of the target or they may be deviating from the target path by making consistently smaller or larger circles [Frith, 1973; Okamoto, 1964]. Recently, computer-based versions of the PR, have overcome these limits, by documenting changes in motor performance strategies in typically developing (TD) children. Van Roon and colleagues using a computer-based version of the PR were able to report that while children between 6 and 9 years of age are able to track a target only at lower velocities, using a feedback-based strategy. With age-growth, use of a feedback-based strat- egy (also termed step-and-go strategy) gradually decreased while use of a feed-forward strategy increased and children passed from using intermittent, step-andgo movements to more smooth and accurate motor tracking [Van Roon, Caeyenberghs, Swinnen, \& SmitsEngelsman, 2008].

To our knowledge, only three studies have used the PR task to measure motor procedure learning in children with ASD, all of them relying on traditional PRs. Frith and Frith [1974] showed similar TT with respect to TD controls in low-functioning autistic children, also highlighting that in ASD performance was correlated to standardized measures of visuomotor coordination [Frith \& Frith, 1974]. Wek and Husak [1989] analyzed if massed practice (i.e., continuous practice of a task with few or no pauses for rest even of short duration relative to work intervals) vs. distributed practice (i.e., practice schedule in which the amount of rest between practice trials is equivalent to the trial length) could affect overall TT in children with ASD, but found no significant differences. Finally, Gidley Larson and Mostofsky [2008] confirmed comparable improvement in TT in children with ASD with respect to TD controls. Interestingly, these authors also highlighted that ASD children's performance was less affected by changes in path shape with respect to controls, when an intervening block of trials with an alternate pattern (i.e., square instead of circle) was introduced [Gidley Larson \& Mostofsky, 2008]. To explain this phenomenon, the authors hypothesized that children with ASD, while showing similar TT, may be resorting to very different performance strategies [Gidley Larson \& Mostofsky, 2008]. However, to date, these strategies have not been further investigated, while other studies suggest that deeper investigation of hidden motor strategies may allow highlighting specific difficulties in children with ASD [Haswell, Izawa, Dowell, Mostofsky, \& Shadmehr, 2009; Izawa, Pekny, Marko, Haswell, Shadmehr, \& Mostofsky, 2012; Gidley Larson, Bastian, Donchin, Shadmer, \& Mostofsky, 2008].

Wishing to extend previous findings, we designed a simple computer-based PR (termed virtual pursuit rotor, VPR), allowing evaluating not only mean TT, but also other performance measures. That is, duration of consecutive time on target (CCT), in order to parse out the presence or absence of a feed-forward-based strategy; distance from target (DT) and distance from path (DP), to provide more information on what participants do when they are off target [Frith, 1973]. Similarly to Gidley Larson and Mostofsky [2008], we measured increased procedural learning across identical blocks of trials and used an intervening "interference" block to evaluate procedure-specific learning. In fact, given the inflexibility and sensitivity to changes of motor procedure learning, one way to evaluate if a specific 
procedure has been acquired is to introduce a change and to measure its interference effect [Gidley Larson \& Mostofsky, 2008]. Differently from previous studies, we conducted a first experiment to assess interference effects offered by altering characteristics of intervening blocks (i.e., changes in target speed vs. track shape) considering only TD children. This first experiment allowed to: evaluate effectiveness of the VPR in measuring motor procedure learning, control for the presence of different performance strategies in TD children, choose most appropriate characteristics for intervening block trials. Main hypotheses for Experiment 1 were that TD children would show similar procedural learning and motor performance strategies across blocks of trials presenting identical stimuli, while changes in intervening block trials would differentially affect task difficulty and lead to diverse interference effects (i.e., changes in speed, would produce less interference on procedure-specific learning). A second experiment was then run including a group of children with ASD and a group of TD controls matched for chronological age (CA) and IQ, also evaluating, for the first time in ASD, consolidation effects after a 24-hour rest. Our main hypotheses for Experiment 2 were that: (1) both groups would show similar patterns of motor procedural learning and that, having changed the intervening block's characteristics, both groups would show similar performance in the intervening block; (2) that the new VPR task would allow to highlight differences in motor execution in children with ASD compared to controls; and (3) that children's performance would be correlated to their scores in other visuo-motor standardized tests.

\section{Method \\ Participants}

Seventy children (54 TD, 16 ASD) with CA between 5;5 and 11;0 (years;months) participated in this study. Children with TD were all primary speakers of Italian had no previous history of language and/or learning disabilities and no presence of ASD diagnosis in any immediate family member as documented by individual questionnaires completed by parents. Documented diagnosis was provided by area clinicians for children with ASD (fourth and fifth authors), confirmed using Autism Diagnostic Observation Schedule [ADOS; Lord et al., 2000; Lord et al., 2005]. For the ASD group mean, ADOS score was 10.56 (SD 2.83); based on this score, 10 of the 16 participants met criteria for ASD, while the remaining 6 met criteria for autism. Intellectual functioning (IQ) was evaluated in all children using Raven's Colored Progressive Matrices task [Raven, Court, \& Raven, 1990] and visuomotor coordination skills were assessed using the Beery Visual Motor Integration Test
(VMI), including the Visual Perception (VP) and the Motor Coordination (MC) subtests [Beery \& Beery, 2004]. All participants displayed an IQ of 70 or above. All children with ASD had good comprehension of verbal instructions during the task and clinical evaluations of verbal skills were available for all participants in the ASD group using standardized tests (with the exception of four children for which data was not available). In particular, five children were evaluated using the Italian standardized version of the Peabody Picture Vocabulary Test - Revised [Dunn \& Dunn, 1981; Stella, Pizzoli, \& Tressoldi, 2000, standard scores above 70, range 74-82]; two children were evaluated using the Italian Test Fono Lessicale (Phono Lexical Test or TFL; Vicari, Marotta, \& Luci, 2007, all scores above $10^{\circ}$ percentile rank in language comprehension), two children were evaluated using the Weschler Intelligence Scale for Children (WISC)-III [Weschler, 1991, Verbal IQ scores of 86 and 130, respectively] and three children were assessed using the WISC-IV [Weschler, 2003, Verbal Comprehension Index of 84, 128, and 140, respectively]. The study was approved by the local Ethical Committee and performed in accordance with the ethical standards laid down by the Declaration of Helsinki. Children with TD were recruited and evaluated at a public primary school in Rome, Italy, and children with ASD were recruited and evaluated at the "Bambino Gesù" Children's Hospital, Rome, Italy. All participants completed two study sessions and had normal or corrected to normal vision. Study purpose was presented and explained to teachers and educators as well as parents of participants, the latter providing informed written consent.

In Experiment 1, 38 TD children (26 girls and 12 boys, mean CA 8 ;9) were subdivided into two groups (comprising 19 children each, balanced for gender), before being randomly assigned to one of two test conditions (i.e., typically developing children performing the "velocity change" condition, or TDV, and typically developing children performing the "shape change" condition, or TDS, respectively). No differences emerged between groups in $\mathrm{CA}, \mathrm{IQ}$, or VMI test and subtests raw scores. In Experiment 2, 16 children with ASD (all boys, mean CA 8;2) and 16 TD controls (all boys, mean CA 8;5) performed the "velocity change" condition. Groups in Experiment 2 were matched for CA and IQ, while a significant difference emerged between groups on VMI, VP, and MC (all Ps $<0.05)$. Demographics of participant groups for Experiments 1 and 2 are summarized in Table 1 .

\section{Materials and Procedure}

The VPR task, is a modified version of the PR test available within the Psychology Experiment Building Language [PEBL; Mueller, 2012] battery. The latter has 
Table 1. Demographical Data, Measures of IQ, and Visuo-Motor Coordination of All Participant Groups

\begin{tabular}{lcccc}
\hline & TDV & TDS & TD & ASD \\
\hline$N$ & 19 & 19 & 16 & 16 \\
Females:Males & $13: 6$ & $13: 6$ & $0: 16$ & $0: 16$ \\
Chronological Age $^{\mathrm{a}}$ & $107.37 \pm 11.83(90-120)$ & $107.84 \pm 12.03(89-120)$ & $101.31 \pm 17.27(69-129)$ & $99.00 \pm 17.23(67-133)$ \\
IQ & $105.26 \pm 11.24(90-130)$ & $108.42 \pm 12.59(90-130)$ & $108.75 \pm 9.57(100-130)$ & $101.25 \pm 17.84(70-130)$ \\
VMI Total Standard Score & $99.63 \pm 13.04(85-137)$ & $97.47 \pm 9.73(85-120)$ & $105.56^{\mathrm{C}} \pm 15.79(85-132)$ & $93.69^{\mathrm{C}} \pm 10.33(78-144)$ \\
$\quad$ VMI-Visual Subtest & $113.95 \pm 18.88(73-142)$ & $108.89 \pm 15.32(81-136)$ & $107.69^{\mathrm{C}} \pm 18.24(69-139)$ & $94.63^{\mathrm{C}} \pm 21.11(56-135)$ \\
$\quad$ Standard Score & $105.11 \pm 8.55(88-121)$ & $103.89 \pm 13.64(74-133)$ & $108.63^{\mathrm{C}} \pm 15.35(82-142)$ & $96.50^{\mathrm{C}} \pm 11.76(71-123)$ \\
$\quad$ VMI-Motor Subtest & - & - & - & $10.56 \pm 2.83(7-16)$ \\
$\quad$ Standard Score & - & & &
\end{tabular}

${ }^{\text {a }}$ Mean chronological age in months \pm standard deviation (range).

${ }^{\mathrm{b}}$ Mean \pm standard deviation (range).

${ }^{\mathrm{c}} P<0.05$

already been tested on children between 9 and 13 years of age [Piper, 2011]. Source code for the VPR is provided in Supporting Information and can be run on the freeware PEBL platform (available at http://pebl.sf.net). In the VPR, children were requested to manually track a blue dot (diameter $1 \mathrm{~cm}$ ) moving clockwise on a computer screen $(13 \times 8$ inch, 1,280 $\times 800$ pixel resolution $)$ using a digitalized pen and tablet (Wacom Bamboo Pen \& Touch CTH-460-DE with 5.8-by-3.6-inch active pen area and 101.6 dpi resolution). Children used the digitalized pen on a white sheet of paper positioned on the tablet to maintain the computer cursor, displayed on the computer screen, on the target. The digitalized tablet included an installation software allowing adjustments for right- or left-handedness and before the task each participant was asked to write down his/her name and a short phrase on a sheet of paper to evaluate hand preference and set the digitalized tablet accordingly. As all children reported that they had never used a similar pen and tablet, before the task began, all participants were given a few practices by moving the pen on the tablet and observing the corresponding movement of the mouse cursor. Children were then instructed to keep the cursor on the blue target dot and that when the cursor was on target the dot would become light up. To render the entire procedure more entertaining, it was presented as a videogame in which the target represented and alien spaceship and the cursor a capturing device, scope of the game being to capture as many aliens as possible by holding the cursor on the spaceship, when aliens were being captured the spaceship would light up. After each block, the program showed a number on the screen indicating TT, which was used to indicate how many aliens had been captured. Target path shape was never visible to reduce explicit visual cueing of the target's movement. The task comprised five blocks of trials. Blocks 1-4 were performed consecutively on the same day, while block 5 was performed at the same time on the next day. All blocks comprised four identical trials each trial requiring tracing for six times a set path shape at a set speed. There was a 20 min pause between blocks 1 and 2 and, unless the participant requested a longer break, pause between other blocks was approximately 2 min. During the 20-min pause, children performed other neuropsychological tests that were part of the study and did not involve writing. Target path and speed were identical in blocks $1,2,4$, and 5, i.e., the target moving in a circle path at $0.17 \mathrm{~Hz}$ (i.e., 10.2 RPM, corresponding to a tangential speed of $4.3 \mathrm{~cm} / \mathrm{sec}$, radius equal to $4 \mathrm{~cm}$ ) and each of these blocks lasted 35294.1 milliseconds (ms). Block 3 was used as intervening block. In the "velocity change" condition, target speed in block 3 was increased to $0.20 \mathrm{~Hz}$ (i.e., $12 \mathrm{RPM}$ or $5.2 \mathrm{~cm} / \mathrm{sec}$ ) and path shape was held constant (i.e., blocks 1, 2, 4, and 5 lasted $35294.1 \mathrm{~ms}$ while block 3 lasted $30000 \mathrm{~ms}$ ), while in the "shape change" condition path shape in block 3 was changed to a square path, while target tangential speed was held constant as well as overall block duration $35294.1 \mathrm{~ms}$. In Experiment 1, the TDV group performed the "velocity change" condition, and the TDS group performed the "shape change" condition. In Experiment 2, both ASD and TD groups performed the "velocity change" condition. As the circle-shaped path had a $4.1-\mathrm{cm}$ radius, while the square-shaped path had $8.1-\mathrm{cm}$ sides, in order to keep the total amount of path traced by children constant during all trials across conditions, duration of each trial was kept constant. All source codes were run at $25 \mathrm{~Hz}$ during the entire procedure.

\section{Dependent Measures and Analyses}

For each trial, the VPR program automatically generated a .txt file with point-by-point indication of: target position (expressed in pixels), cursor position (expressed in pixels), elapsed time (expressed in ms), total TT (expressed in ms), and mean deviation from target (expressed in pixels). All 

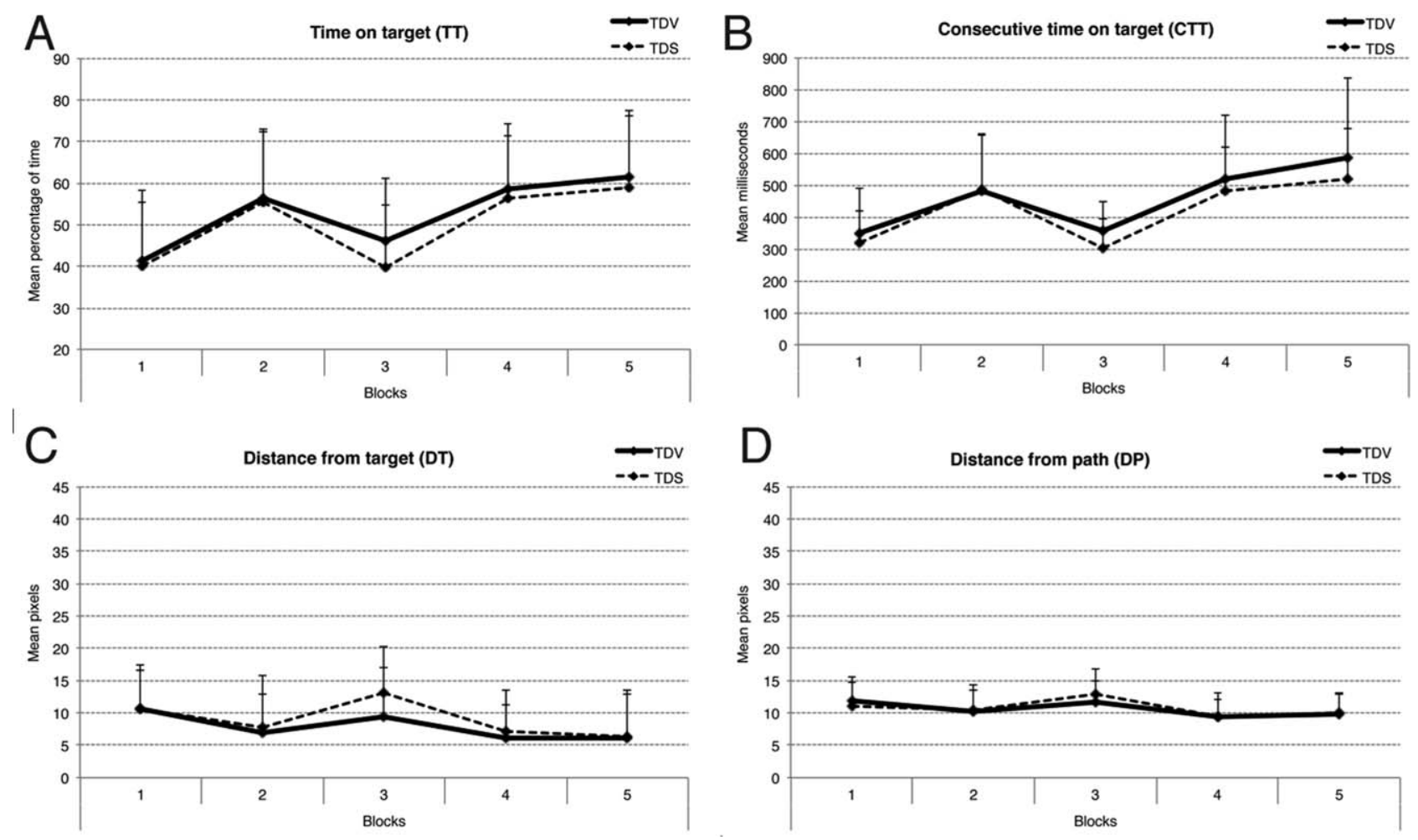

Figure 1. Plots of TD groups' performance in the "velocity condition" and in the "shape condition" across all blocks of trials for Experiment 1.

data were analyzed using MATLAB. Means of four measures of performance in relation to the target were considered for each participant in each block: TT (calculated as a percentage of the total time, as some blocks differed in overall time), continuous time on target (CTT; measured in ms), DT (measured in pixels), and DP (measured in pixels). 2D reconstructions of children's trajectories were also used for qualitative data analyses (see also Figs. 3 and 4). All analyses were carried out using the Statistical Package for the Social Sciences, release 19.0.0 (IBM SPSS Inc., Chicago, IL). Separate analyses were conducted for Experiments 1 and 2. All data were checked for normality using Shapiro-Wilks W-test, separately for the four experimental groups. DT and DP values were analyzed after $\log 10-$ trasformation to meet criteria for parametric analysis; however, all data reported in both text and figures reflect the untransformed means. Changes in mean TT, CTT, DT, and DP were analyzed separately using repeated measures analyses of valiance (ANOVAs). To assess interference effects in intervening block 3, we subtracted groups' performance in block 3 from their expected performance in absence of interference. The latter was calculated as the mean between performance in blocks 2 and 4 (i.e., (Block $2+$ Block 4)/2). An alpha level of $P<0.05$ was used to reject the null hypothesis. Effect size (partial eta square, $\eta_{\mathrm{p}}^{2}$ ) was included. Associations across measures were assessed using Spearman correlation methods.

\section{Results}

\section{Experiment 1}

Groups overall patterns of procedural learning were measured as changes in TT across blocks 1-4. Repeated measures analysis of variance (ANOVA) with blocks (14) as dependent variable and groups (TDV, TDS) as independent variable, showed a significant effect of blocks $\left(F_{(3,34)}=143.300 ; P<0.000 ; \eta_{\mathrm{p}}^{2}=0.927\right)$ indicating changes in performance across blocks of trials, no groups effect $\left(F_{(1,36)}=0.329 ; P=0.570 ; \eta_{\mathrm{p}}^{2}=0.009\right)$ and significant interaction effect $\left(F_{(3,34)}=3.728 ; P=0.020\right.$; $\left.\eta_{\mathrm{p}}^{2}=0.248\right)$, highlighting that changes in performance across blocks of trials differed among groups. Pairwise comparisons between blocks across groups, showed significant differences between all blocks (all Ps $<0.000$ ), except between blocks 1 and $3(P<0.526)$ and blocks 2 and $4(P<0.945)$. Plots of groups' performance across blocks of trials as shown in Figure 1 suggested that interaction effect was due to a difference between groups in the intervening block 3 which differed in the "velocity change" and in the "shape change" condition. One-way ANOVA between groups (TDV, TDS) on interference effect in TT (calculated as described above), showed significant difference in interference effect between groups $\left(F_{(1,36)}=10.33 ; P<0.004 ; \eta_{\mathrm{p}}^{2}=0.22\right)$, with "shape change" condition leading to significantly 
Table 2. Summary of Results for Experiment 1

\begin{tabular}{|c|c|c|c|c|c|}
\hline Group & Block 1 & Block 2 & Block 3 & Block 4 & Block 5 \\
\hline \multicolumn{6}{|c|}{ Mean $\%$ of time on target } \\
\hline TDV & $41.26( \pm 16.89)$ & $56.48( \pm 15.92)$ & $46.11( \pm 15.21)$ & $58.64( \pm 15.50)$ & $61.34( \pm 16.24)$ \\
\hline TDS & $39.95( \pm 15.38)$ & $55.32( \pm 17.72)$ & $39.63( \pm 15.10)$ & $56.23( \pm 15.04)$ & $58.95( \pm 17.21)$ \\
\hline \multicolumn{6}{|c|}{ Mean consecutive time on target (ms) } \\
\hline TDV & $350.91( \pm 139.02)$ & $482.83( \pm 174.72)$ & $355.72( \pm 93.79)$ & $519.68( \pm 198.69)$ & $585.37( \pm 249.50)$ \\
\hline TDS & $320.51( \pm 98.29)$ & $488.29( \pm 174.36)$ & $301.78( \pm 91.75)$ & $482.16( \pm 136.84)$ & $520.22( \pm 156.55)$ \\
\hline \multicolumn{6}{|c|}{ Mean distance from target (pixels) } \\
\hline TDV & $10.55( \pm 6.04)$ & $7.02( \pm 5.94)$ & $9.51( \pm 7.51)$ & $6.13( \pm 5.18)$ & $6.09( \pm 6.81)$ \\
\hline TDS & $10.70( \pm 6.74)$ & $7.69( \pm 8.14)$ & $13.17( \pm 7.06)$ & $7.13( \pm 6.46)$ & $6.36( \pm 7.14)$ \\
\hline \multicolumn{6}{|c|}{ Mean distance from path (pixels) } \\
\hline TDV & $11.96( \pm 3.58)$ & $10.30( \pm 3.15)$ & $11.58( \pm 3.31)$ & $9.38( \pm 2.63)$ & $9.91( \pm 3.11)$ \\
\hline TDS & $11.11( \pm 3.68)$ & $10.45( \pm 3.84)$ & $12.97( \pm 3.70)$ & $9.47( \pm 2.99)$ & $9.95( \pm 3.34)$ \\
\hline
\end{tabular}

higher interference in TT (mean interference effect $16.2 \%$ ) than "velocity change" (mean interference effect $11.5 \%$ ).

Three separate repeated measures ANOVAs were run, evaluating changes in CTT, DT, DP in blocks (1-4) between groups (TDV, TDS). Analysis on CTT showed significant effect of blocks $\left(F_{(3,34)}=46.443 ; P=0.000\right.$; $\left.\eta_{\mathrm{p}}^{2}=0.804\right)$, but no group effect $\left(F_{(1,36)}=0.501 ; P=\right.$ $\left.0.484 ; \eta_{\mathrm{p}}^{2}=0.014\right)$ and no interaction effect $\left(F_{(3,34)}=\right.$ 1.150; $\left.P=0.343 ; \eta_{\mathrm{p}}^{2}=0.092\right)$. Although analyses on DT and DP showed significant effects of blocks $\left(F_{(3,34)}=\right.$ 41.092; $P<0.000 ; \eta_{\mathrm{p}}^{2}=0.784$ and $F_{(3,34)}=30.207 ; P<$ $0.000 ; \eta_{\mathrm{p}}^{2}=0.727$, respectively), no significant effect of groups $\left(F_{(1,36)}=0.179 ; P=0.494 ; \eta_{\mathrm{p}}^{2}=0.013\right.$ and $F_{(1,36)}$ $=0.019 ; P=0.892 ; \eta_{\mathrm{p}}^{2}=0.001$, respectively), and significant interaction effect $\left(F_{(3,34)}=4.572 ; P<0.00 ; \eta_{\mathrm{p}}^{2}=\right.$ 0.287 and $F_{(3,34)}=3.238 ; P=0.034 ; \eta_{\mathrm{p}}^{2}=0.222$, respectively). Groups' performance across blocks of trials, as shown in Figure 1, suggested that interaction effects were once more due to a difference between groups in the intervening block 3. Two one-way ANOVAs on interference affect of the intervening block 3 in DT and DP between groups (TDV, TDS), showed a significant interference effect in both DT and DP $\left(F_{(1,36)}=8.182 ; P\right.$ $=0.007 ; \eta_{\mathrm{p}}^{2}=0.185$ and $F_{(1,36)}=5.434 ; P=0.025 ; \eta_{\mathrm{p}}^{2}=$ 0.131 , respectively), with "shape change" condition leading to more DT and path than "velocity change."

Finally, to measure consolidation effects repeated measures ANOVA with blocks (4 and 5) as dependent variables and groups (TDV, TDS) as independent variable was run, showing significant effect of blocks $\left(F_{(1,36)}\right.$ $\left.=4.181 ; P=0.048 ; \eta_{\mathrm{p}}^{2}=0.104\right)$, no effect of group $\left(F_{(1,36)}=0.228 ; P=0.636 ; \eta_{\mathrm{p}}^{2}=0.006\right)$, and no interaction effect $\left(F_{(1,36)}=0.000 ; P=0.995 ; \eta_{\mathrm{p}}^{2}=0.000\right)$. Both groups showed a higher performance after $24 \mathrm{hr}$ (i.e., mean percentage of TT in block 4 was $58.6 \%$ for the TDV and $56.2 \%$ for the TDS, while in block 5 it reached $61.3 \%$ for the TDV group and 59\% for the TDS group). Groups' performance across blocks of trials in Experiment 1 is summarized in Table 2 .

\section{Experiment 2}

Differences between groups in overall procedural learning were measured as changes in TT across blocks (1-4). Repeated measures ANOVA with blocks (1-4) as dependent variable and groups (TD, ASD) as independent variable, showed a significant effect of blocks $\left(F_{(3,28)}\right.$ $\left.=40.728 ; P<0.000 ; \eta_{\mathrm{p}}^{2}=0.814\right)$, indicating different performance across blocks of trials, effect of groups approaching significance $\left(F_{(1,30)}=4.088 ; P=0.052\right.$; $\left.\eta_{\mathrm{p}}^{2}=0.120\right)$, and interaction effect showing a trend toward significance $\left(F_{(3,28)}=2.625 ; P=0.070 ; \eta_{\mathrm{p}}^{2}=\right.$ 0.219). Pairwise comparisons across groups, showed that groups performance differed between all blocks (all Ps $<0.000)$, except between blocks 2 and $4(P<0.058)$ where differences only approached significance. Plots of children's performance across blocks as shown in Figure 2 , suggested a difference in the intervening block 3 . One-way ANOVA between groups (TD, ASD) on interference effect on TT in block 3 , showed a significant difference between groups $\left(F_{(1,30)}=4.935 ; P=0.034 ; \eta_{\mathrm{p}}^{2}=\right.$ $0.141)$, with velocity change leading to more interference for the TD group (mean interference effect $10.18 \%$ ) than for the ASD group (mean interference effect $6.25 \%$ ).

Three separate repeated measures ANOVAs were run considering changes in CTT, DT, DP in blocks (1-4) between groups (TD, ASD). Analysis on CTT showed a significant effect of blocks $\left(F_{(3,28)}=25.005 ; P=0.000\right.$; $\left.\eta_{\mathrm{p}}^{2}=0.728\right)$, no groups effect $\left(F_{(1,30)}=3.013 ; P=0.093\right.$; $\left.\eta_{\mathrm{p}}^{2}=0.091\right)$, and significant interaction effect $\left(F_{(3,28)}=\right.$ 3.170; $\left.P=0.040 ; \eta_{\mathrm{p}}^{2}=0.254\right)$. Once again the plots as shown in Figure 2, suggested that this was due to different degree of interference in block 3. One-way ANOVA comparing interference effect on CTT in block 3 between groups (TD, ASD), showed significant difference between groups $\left(F_{(1,30)}=5.323 ; P=0.028 ; \eta_{\mathrm{p}}^{2}=\right.$ $0.151)$. Analysis on DT and DP showed significant differences across blocks $\left(F_{(3,28)}=13.707 ; P<0.000 ; \eta_{\mathrm{p}}^{2}=\right.$ 0.595 and $F_{(3,28)}=16.193 ; P<0.000 ; \eta_{\mathrm{p}}^{2}=0.634$, 
Table 3. Summary of Results for Experiment 2

\begin{tabular}{|c|c|c|c|c|c|}
\hline Group & Block 1 & Block 2 & Block 3 & Block 4 & Block 5 \\
\hline \multicolumn{6}{|c|}{ Mean $\%$ of time on target } \\
\hline TD & $39.14( \pm 17.08)$ & $53.92( \pm 17.88)$ & $44.39( \pm 15.83)$ & $55.22( \pm 15.36)$ & $60.27( \pm 16.15)$ \\
\hline ASD & $25.56( \pm 13.66)$ & $38.52( \pm 19.54)$ & $35.41( \pm 19.13)$ & $44.81( \pm 20.98)$ & $49.36( \pm 19.90)$ \\
\hline \multicolumn{6}{|c|}{ Mean consecutive time on target (ms) } \\
\hline TD & $311.46( \pm 103.88)$ & $478.75( \pm 166.22)$ & $354.47( \pm 92.34)$ & $491.65( \pm 183.22)$ & $565.63( \pm 284.11)$ \\
\hline ASD & $246.47( \pm 85.04)$ & $348.50( \pm 151.93)$ & $311.94( \pm 128.02)$ & $403.79( \pm 217.64)$ & $458.19( \pm 274.65)$ \\
\hline \multicolumn{6}{|c|}{ Mean distance from target (pixels) } \\
\hline TD & $12.16( \pm 8.80)$ & $7.68( \pm 6.82)$ & $9.86( \pm 8.09)$ & $6.97( \pm 4.58)$ & $5.56( \pm 3.76)$ \\
\hline ASD & $26.39( \pm 17.65)$ & $19.95( \pm 18.15)$ & $21.30( \pm 20.45)$ & $13.91( \pm 13.44)$ & $11.68( \pm 10.88)$ \\
\hline \multicolumn{6}{|c|}{ Mean distance from path (pixels) } \\
\hline TD & $12.78( \pm 4.73)$ & $10.72( \pm 3.53)$ & $12.22( \pm 4.23)$ & $9.74( \pm 2.80)$ & $9.49( \pm 2.84)$ \\
\hline ASD & $19.55( \pm 8.47)$ & $18.40( \pm 13.29)$ & $18.83( \pm 11.68)$ & $14.12( \pm 7.77)$ & $13.76( \pm 6.72)$ \\
\hline
\end{tabular}

respectively), significant difference between groups $\left(F_{(1,30)}=6.226 ; P=0.018 ; \eta_{\mathrm{p}}^{2}=0.172\right.$ and $F_{(1,30)}=$ 7.513; $P=0.010 ; \eta_{\mathrm{p}}^{2}=0.200$, respectively), and no interaction effect $\left(F_{(3,28)}=1.755 ; P=0.179 ; \eta_{\mathrm{p}}^{2}=0.158\right.$ and $F_{(3,28)}=0.503 ; P=0.683 ; \eta_{\mathrm{p}}^{2}=0.051$, respectively).

Finally, to measure consolidation effects, repeated measures ANOVA with blocks (4 and 5) as dependent variables and groups (TD, ASD) as independent variable was run, showing a significant effect of blocks $\left(F_{(1,30)}=\right.$ $\left.14.509 ; P=0.001 ; \eta_{\mathrm{p}}^{2}=0.326\right)$, no effect of group $\left(F_{(1,30)}\right.$ $\left.=2.838 ; P=0.102 ; \eta_{\mathrm{p}}^{2}=0.086\right)$, and no interaction effect $\left(F_{(1,30)}=0.039 ; P=0.844 ; \eta_{\mathrm{p}}^{2}=0.001\right)$. In fact, both ASD and TD children showed a higher performance after $24 \mathrm{hr}$ (i.e., mean percentage of TT in block 4 was $44.8 \%$ for the ASD and $55.2 \%$ for the TD, while in block 5 it reached $49.4 \%$ for the ASD group and $60.3 \%$ for the TD group). Groups' performance across blocks of trials in Experiment 2 is summarized in Table 3.

Spearman's correlations were run to determine: (1) the relationship between group characteristics (i.e., CA, IQ, VMI, ADOS severity) and measures of performance in the VPR task (i.e., TT, CTT, DT, DP) in block 1 and (2) the relationship between group characteristics (i.e. CA, IQ, VMI, ADOS severity) and groups' learning of a motor procedure, measured as percentage of change in TT between block 1 and block 2 across all performance measures (i.e., TT, CTT, DT, DP), as reported in Table 4. In the TD group, strong correlations emerged between CA and all measures of performance in the VPR task (TT: $r_{\mathrm{s}}=0.690, n=16, P=0.003$; CTT: $r_{\mathrm{s}}=0.736, n=$ 16, $P=0.001$; DT: $r_{\mathrm{s}}=-0.808, n=16, P=0.000$; DP: $\left.r_{\mathrm{s}}=-0.671, n=16, P=0.004\right)$. In the ASD group, moderate correlations or correlations approaching significance emerged between CA and all measures of performance in the VPR task (TT: $r_{\mathrm{s}}=0.532, n=16, P=$ 0.034; CTT: $r_{\mathrm{s}}=0.566, n=16, P=0.022$; DT: $r_{\mathrm{s}}=$ -0.491, $n=16, P=0.054 ; \mathrm{DP}: r_{\mathrm{s}}=-0.519, n=16, P$ $=0.039)$. In the ASD group, there was also a moderate correlation between IQ and both TT $\left(r_{\mathrm{s}}=0.598, n=\right.$
16, $P=0.014)$ and DT $\left(r_{\mathrm{s}}=-0.510, n=16, P=\right.$ $0.510)$. Strong correlations emerged in the ASD group between the VMI visual subtest and TT, DT, and DP (i.e., TT: $r_{\mathrm{s}}=0.670, n=16, P=0.005$; DT: $r_{\mathrm{s}}=$ -0.636, $n=16, P=0.008$; DP: $r_{\mathrm{s}}=-0.696, n=16, P$ $=0.003)$, while CTT approached significance (CTT: $r_{\mathrm{s}}=$ $-0.483, n=16, P=0.058)$. Finally, a moderate correlation was present only in the ASD group between CA and increase in performance as measured by CTT between blocks 1 and $2\left(r_{\mathrm{s}}=0.585, n=16, P=0.017\right)$.

\section{Discussion \\ Experiment 1}

Changes in TT across blocks of trials were present in both TD groups, proving VPR settings appropriate in measuring motor procedure learning in children between 7 and 10 years of age. Van Roon et al. [2008], report that TD 7-year-olds are able to track a target moving in a circle path with $3-\mathrm{cm}$ radius at a maximum speed of $7.2 \mathrm{~cm} / \mathrm{sec}$. Using a slightly larger radius (4.1 $\mathrm{cm})$ and slightly slower speed ( 4.3 or $5.2 \mathrm{~cm} / \mathrm{sec}$ ), we were able to provide a task that would not prove frustrating, while allowing learning, as shown by difference in groups' performance between blocks 1 and 2 and interference effect of block 3 for both groups. Increment in performance was not simply due to growing familiarity with the task, as children were able to maintain the acquired skill after interference, as shown by similar groups' performance in blocks 2 and 4 .

Consistent with our second hypothesis, "speed change" vs. "shape change" conditions lead to different interference effects, as children were more affected by a change in path shape. This result is in line with early PR studies, which reported that shapes with sharp changes of direction (i.e., square and triangular) were more complex than circular forms for TD children between 6 and 9 years of age [Eckert, 1974; Neiner, 1971]. Similarly to Gidley Larson and Mostofsky [2008], 
Table 4. Correlations Between Performance of TD and ASD Children in Experiment 2 in the VPR Task Valuated as TT, CTT, DT and DB in Block 1 and CA, IQ, VMI, and ADOS scores

\begin{tabular}{|c|c|c|c|c|c|c|c|c|}
\hline Group & TD & ASD & TD & ASD & TD & ASD & TD & ASD \\
\hline Measures (Block 1) & \multicolumn{2}{|c|}{ TT } & \multicolumn{2}{|c|}{ CTT } & \multicolumn{2}{|c|}{ DT } & \multicolumn{2}{|c|}{ DP } \\
\hline Chronological Age $\mathrm{e}^{\mathrm{a}}$ & $0.690 * *$ & $0.532^{*}$ & $0.736^{* *}$ & $0.566^{*}$ & $-0.808^{* *}$ & -0.491 & $-0.671^{* *}$ & $-0.519 *$ \\
\hline $\mathrm{I} \mathrm{O}^{\mathrm{b}}$ & 0.253 & $0.598^{*}$ & 0.250 & 0.383 & -0.256 & $-0.510^{*}$ & -0.434 & -0.435 \\
\hline VMI Total Standard Score & 0.016 & -0.156 & 0.004 & -0.239 & -0.059 & 0.091 & -0.183 & -0.159 \\
\hline Visual Subtest Standard Score & 0.028 & 0.670 ** & 0.177 & 0.483 & -0.012 & $-0.636^{* *}$ & -0.127 & $-0.696^{* *}$ \\
\hline Motor Subtest Standard Score & 0.018 & -0.251 & 0.079 & -0.203 & 0.016 & 0.008 & -0.132 & 0.203 \\
\hline ADOS Total & - & -0.139 & - & 0.007 & - & 0.145 & - & 0.363 \\
\hline Communication & - & -0.292 & - & -0.158 & - & 0.269 & - & 0.471 \\
\hline Social Interaction & - & -0.024 & - & 0.116 & - & 0.058 & - & 0.307 \\
\hline Play & - & -0.199 & - & -0.117 & - & 0.223 & - & 0.317 \\
\hline Stereotypies & - & 0.340 & - & 0.300 & - & -0.261 & - & -0.218 \\
\hline
\end{tabular}

* Correlation is significant at $P<0.05$ level (two-tailed); ${ }^{* *}$ Correlation is significant at $P<0.01$ level (two-tailed).

TD children's performance dropped by more than $15 \%$ upon encountering a change in track shape. However, to our knowledge, this is the first time that different interference effects have been compared in a computerbased PR, therefore, extending previous data, our results may be of use in planning future experiments considering both typical and atypical populations.

In Experiment 1, assessing different performance measures beyond TT, proved very useful in understanding why the change to a square path shape led to greater interference effects. In fact, considering not only child- ren's overall TT, but also their ability to continuously track the moving target (CTT) and their skills in staying close to the target and its path (i.e., DT and DP, respectively) brought to light that when children had to cope with an angular path, reduced performance in TT was due to the fact that staying close to the target and/or to its path proved harder, while children's overall smoothness in tracking was less affected (as shown by differences in interference levels in DT and DP between groups and lack of an equivalent difference in CTT). Furthermore, 2D reconstructions of children's trajectories
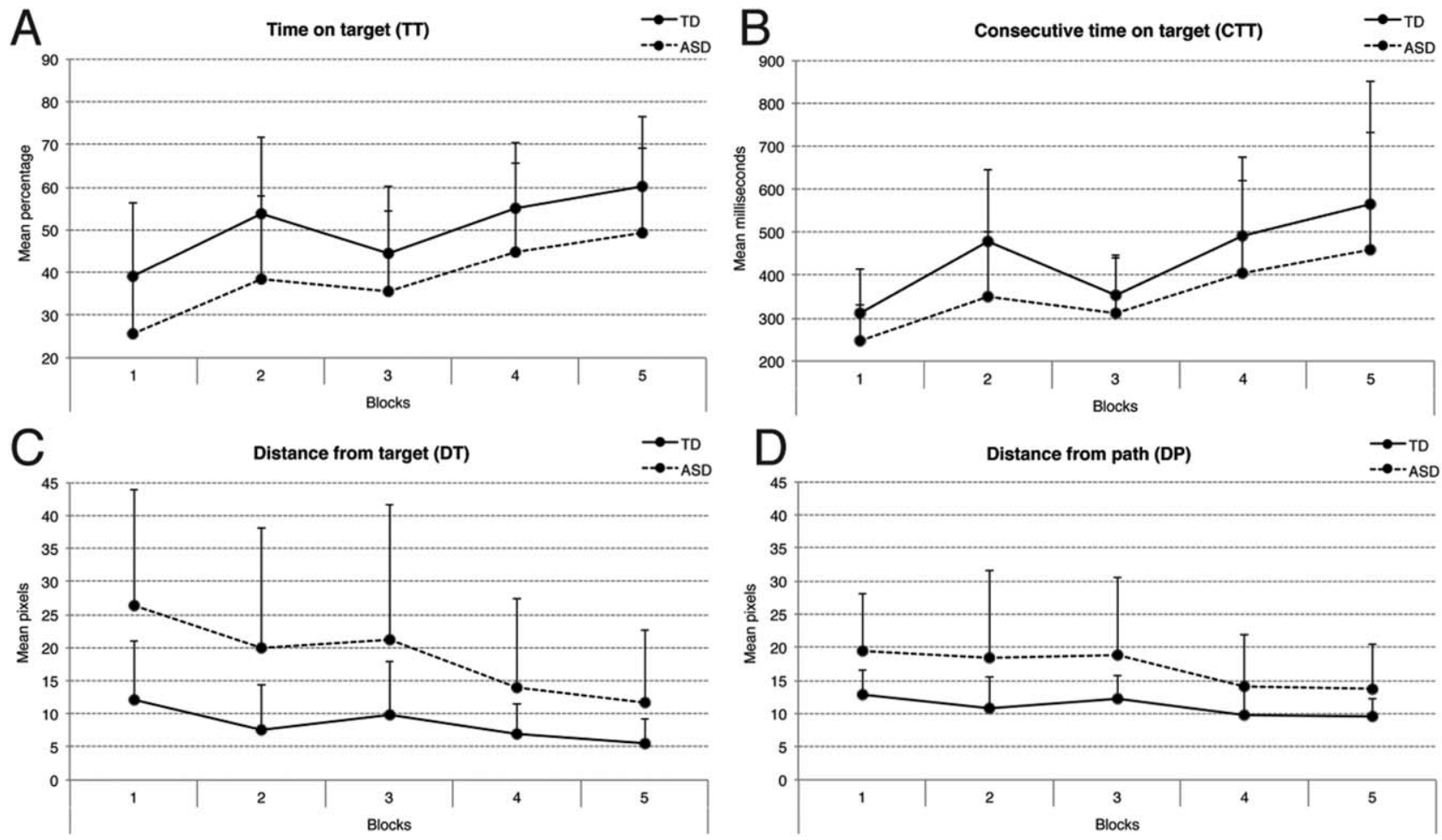

Figure 2. Plots of ASD and TD groups' performance in the "velocity condition" across all blocks of trials for Experiment 2. 


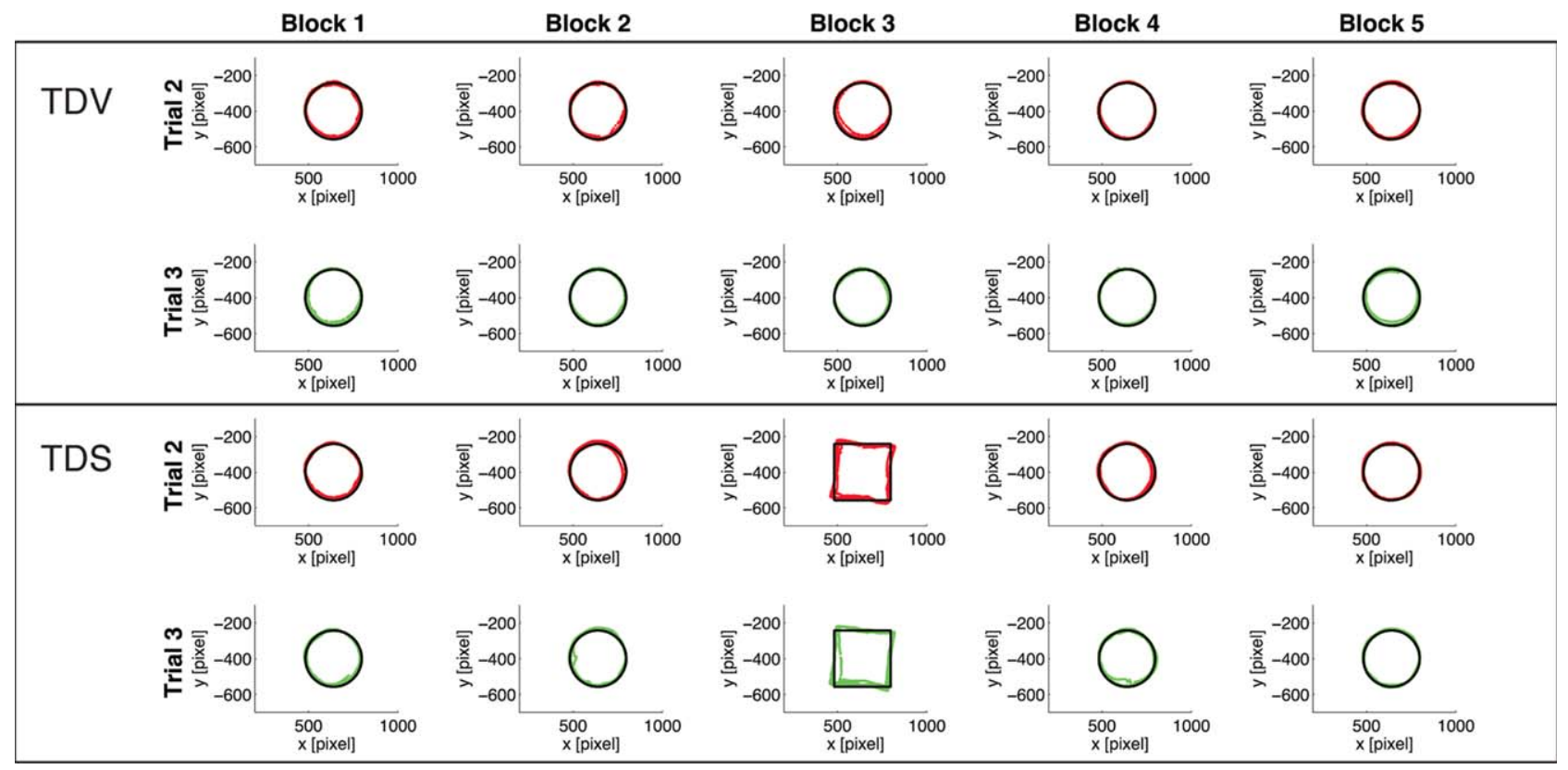

Figure 3. $2 \mathrm{D}$ representation of mean groups trajectories in Experiment 1 for the "velocity change" (TDV) and "shape change" condition in trials 2 and 3 within blocks $1-5$.

showed that, when faced with the square path, children consistently tended to overshoot the target when changes of direction occurred (i.e., when the target reached the square's angles, making a sharp $90^{\circ}$ turn, children tended to proceed in a straight line only to perform rapid adjustments shortly afterward; see Fig. 3). This behavior was consistent across trials, resulting in a "noisier" execution and "tilted" square track, and may allow understanding difficulties documented by previous studies in tracking angular vs. circular paths in TD children. In consideration of the fact that previous studies had already used a square path as the intervening block, reporting difference in interference levels between ASD and TD groups, and wishing to reduce to a minimum the amount of "noise" produced by the characteristics of the intervening stimuli, we chose to use the "speed change" condition in assessing procedural learning in children with ASD in Experiment 2.

Finally, in Experiment 1 both TD groups showed a better performance after a 24-hour rest period. Hsu and Bishop [2014] assessed maintenance effects using a computer-based PR task after a 5-7 days pause, reporting that TD children between 7 and 11 years of age improve their performance. Our data extend this finding by showing that consolidation effects can be measured also after a shorter rest period. Overall, Experiment 1 was essential in order to evaluate efficacy of the VPR task, also allowing appropriate selection of intervening stimuli and confirming the importance of providing other measures of performance (beyond TT) to correctly evaluate children's strategies.

\section{Experiment 2}

Consistent with our first hypothesis children with ASD and children with TD displayed similar patterns of procedural learning (both groups' showing improvements in performance over time across all outcome measures). Once again this increase in performance was not due to increased familiarity with the task, as both groups were able to maintain the acquired skills after interference (as shown by similar groups' performance in TT in blocks 2 and 4). Furthermore, consolidation effects after a 24-hour rest showed that both groups increased their overall TT on the next day. These data are in line with previous studies documenting unimpaired procedural learning and absence of consolidation deficits in ASD, assessed also using other techniques [Foti, De Crescenzo, Vivanti, Menghini, \& Vicari, 2014; Nemeth et al., 2010]. In particular, present data indicate that children with ASD can be taught to perform simple motor procedures using low-cost and portable technology (i.e., a computer, a digitalized pen, and a tablet) improving their performance in time and that rest periods allow for better performance. These results are particularly relevant as motor procedure learning underlies the development of social communicative skills that are often impaired in ASD. In particular, the VPR involved learning to execute fine-motor-control patterns with a pen similar to the ones described as involved in handwriting [Cornhill \& Case-Smith, 1996; Klein, Guiltner, Sollereder, \& Cui, 2011; Tseng \& Cermak, 1993; Volman et al., 2006; Weintraub \& Graham, 2000] and 
A
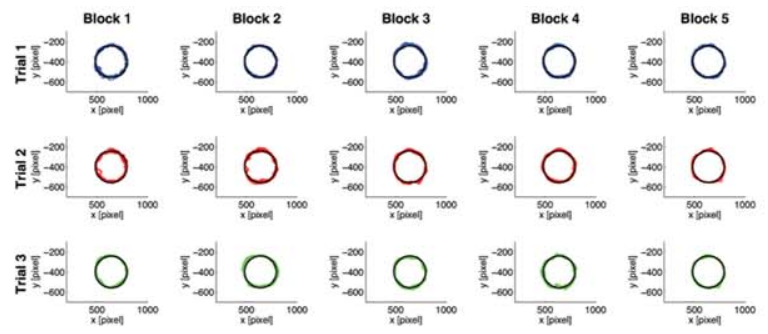

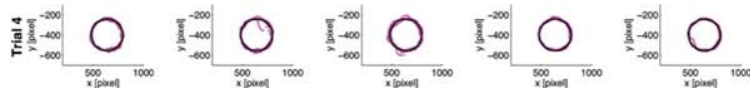

C

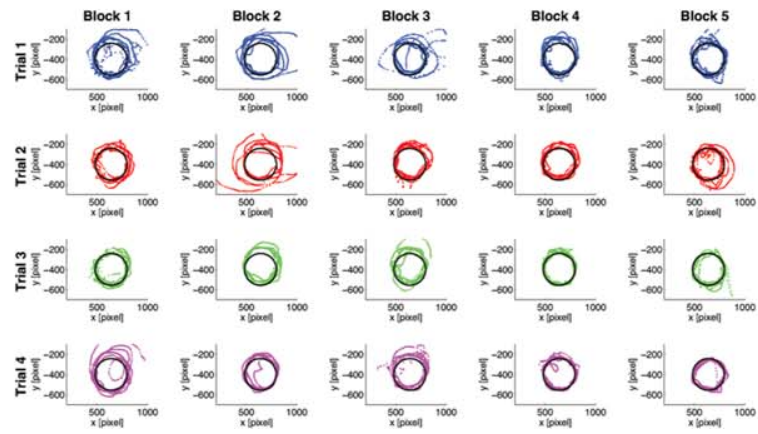

B

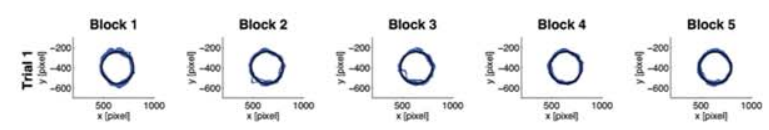

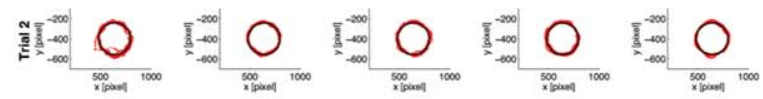

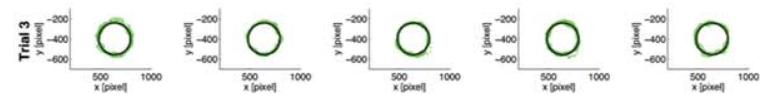

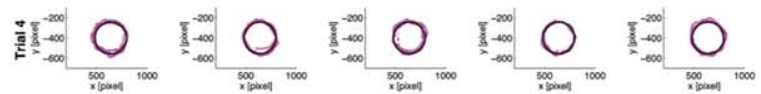

D

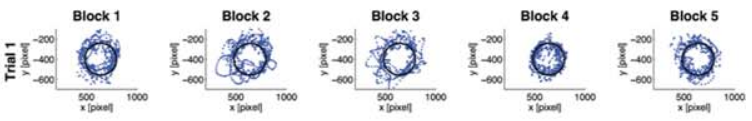

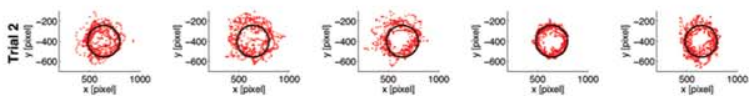

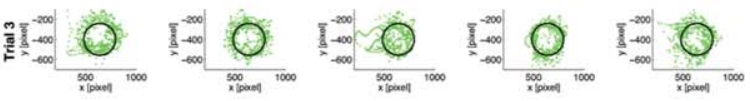

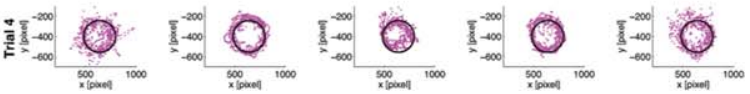

Figure 4. 2D representation of individual children's trajectories in Experiment 2 showing, respectively: (A) average performance of a child in the TD group; (B) child in the ASD group showing imprecise tracking; (C) child in the ASD group drawing smaller of larger circular trajectories; and (D) child in the ASD group adopting a "scribbling" strategy.

handwriting skills have often been reported to be impaired in children with ASD [Kushki, Chau, \& Anagnostou, 2011]. Therefore, our current endeavor is to extend these preliminary findings by developing a simple computer-based program allowing analyzing if exposure to specific motor procedures learning may scaffold handwriting skills in children with ASD. Further studies should also consider if teaching different types of motor procedures might be used in therapy to support other sociocommunicative skills (e.g., gestures and language).

However, even if children in our ASD group showed improvements in performance, the task was significantly harder for them compared to controls (between groups difference in TT across blocks approaching significance). This difference between groups in TT may be explained considering differences in overall visuomotor skills; in fact, even if groups were matched for $\mathrm{CA}$ and IQ, they differed in VMI, VP, and MC tests performance, while correlations emerged only in the ASD group between performance in the VMI visual subtest and performance measures on the VPR task. Similarly, Frith and Frith [1974] reported correlation between PR task results and ASD children's performance in standardized visuo-motor tests. Furthermore, various studies document that visuo-motor integration is a weakness relative to IQ in children with ASD, who usually per- form more poorly than TD controls in the VMI task [Dickerson, Mayes, \& Calhoun, 2003a, 2003b, 2007].

Having chosen to use the "velocity change" condition, we expected to find similar performances in block 3 between groups. However, this hypothesis was not confirmed, as children with ASD proved to be significantly less affected by the change in target speed than TD children. This strengthens previous reports of differences in interference effects between ASD and TD children [Gidley Larson \& Mostofsky, 2008]. To account for this data, we investigated if children with ASD, while showing overall similar TT in blocks 1, 2, and 4, resorted to different motor performance strategies.

Interestingly, significant differences emerged between ASD and TD groups in motor execution during learning. Confirming our initial claim that even if evidence of general improvements in procedural learning may be found in children with ASD, pursuing a full understanding of motor procedure learning in this population may prove to be a more complex task, requiring an analysis of specific motor strategies exploited by children with ASD. In particular, children with ASD in our study were able to stay for continuous periods of TT, showing comparably smooth pursuit tracking (no significant difference between groups in CTT). However, they were overall less precise and less able to keep close to the target and to its path (significant differences between 
groups in DT and DP across all blocks). Qualitative analyses of children's 2D trajectories highlighted relevant differences in performance strategies. Children with TD produced similar trajectories (see Fig. 4, panel A), while ASD children showed overall three distinguishable behaviors: (1) general reduced degree of precision in being on target or on the target's path (similar to the one displayed by some children in the TD group); (2) imprecise tracking of target path, producing smaller or wider circular trajectories; and (3) "scribbling" movements, leading to continuative series of pen strokes perpendicular to the target's path (see Fig. 4, panels B, C, and $\mathrm{D}$, respectively). Interestingly, the latter two behaviors were never observed in TD children. Furthermore, adopting any of these behaviors would allow children with ASD to eventually spend continuous lapses of TT (explaining the lack of group difference in CTT), but would also increase their overall distance from the target and from its path (leading to group differences in DT and DP).

How can we explain presence of these behaviors in the ASD group? Fatigue in sustaining attention and in staying on task can be excluded, given the short duration of the task and consistent presence of described behaviors from the first trial (see Fig. 4). Another hypothesis is that children with ASD experienced difficulties in using external feedback to guide actions. In particular, various studies have shown that children with autism have difficulties in using visual control, therefore, often displaying an overreliance on proprioception [Haswell et al., 2009; Izawa et al., 2012; Masterton \& Biederman, 1983]. We attempted to reduce the amount of visual feedback to a minimum in the VPR (e.g., avoiding presenting the target's path), so that the only feedback that children did receive was from seeing the cursor and from the target lighting up when the child was on target. Furthermore, hypothesizing a specific difficulty in dealing with visual feedback, does not explain the presence of a difference between groups in DT and DP and the lack thereof in CTT. However, we cannot completely rule out this hypothesis, especially considering the strong negative correlation that emerged in children with ASD between performance in the VP subtest and both DT and DP. Further investigations are needed to fully assess this hypothesis. For example, future studies may consider measuring gaze during the VPR track using eye-tracking.

A third hypothesis may consider instead the role of reward in learning a novel task. The only type of reward present in the VPR task was given by the fact that the target changed color when the cursor was correctly placed on it and that children were told that this meant that they were capturing aliens. Therefore, while CTT was a directly rewarding activity, as the target would light up for longer periods (i.e., more aliens would be captured), being able to represent the target's overall path was only an indirectly efficient strategy. As children were never explicitly asked to represent the target path or presented with it, children with ASD may have found other strategies (i.e., drawing larger or smaller circles or scribbling) more immediately rewarding, and may have resorted to them from the start never ceasing to use them. However, this explanation is unable to account for the fact that these strategies were never observed in the TD group. Furthermore, it is surprising that the "scribbling" strategy, once adopted by some ASD children, was not abandoned, requiring very demanding arm movements on the wrist. A study on procedural learning by Watanabe, Ikeda, \& Miyao [2010] may explain this behavior, highlighting that children with ASD while being able to learn a specific visuo-motor sequence, improving both pattern and speed, tend to perseverate in their errors, showing a significantly higher repeated error ratio than TD controls.

Finally, a fourth possibility is that children with ASD were only able to plan short sequences of acts resulting in similar CTT, but were unable to achieve coordination of separate sequences into a precise overall action, resulting in overall greater DT and DP. Having only limited planning of the target's path, ASD children's tracks could easily result in broader or smaller circles or lead to an alternative strategy (i.e., scribbling) to solve the task. Studies on motor planning deficits in children with ASD support this hypothesis, by showing difficulties in coordinating separate acts into a goal-directed action sequence [Cattaneo et al., 2007; Fabbri-Destro, Cattaneo, Boria, \& Rizzolatti, 2009; Forti, Valli, Pergo, Nobile, Crippa, \& Molteni, 2011; Hughes, 1996; Von Hofsten \& Rosander 2012]. Similarly, studies on handwriting skills in children with ASD highlight specific difficulties in overall planning of letters' shape [Fuentes, Mostofsky, \& Bastian, 2009].

Further studies are needed to fully evaluate these hypotheses. However, data from the VPR task confirm the hypothesis advanced by Gidley Larson and Mostofsky [2008], that despite an overall ability to improve performance over time, children with ASD differ in their motor execution patterns. These differences in how children with ASD improve their performance as measured in the VPR task are not only relevant per se, but may increase understanding of how specific motor difficulties in ASD may lead to differences among groups. In particular, our results may also allow explaining differences in interference effects. In fact, children with ASD while being able to spend continuous lapses of time on the target, display specific difficulties in achieving precise overall planning and "proceduralization" of action sequences. These difficulties may be grounded in specific impairments in brain areas involved in motor procedure learning and in the 
formation of action models [Mostofsky \& Ewen, 2011]. Studies investigating brain activation during traditional PR tasks in right-handed TD adults report that initial motor execution leads to activation of areas in the left and right motor cortex responsible for shoulder and finger movements, left and right pre-supplementary motor areas (pre-SMA), basal ganglia, cerebellum, and occipital lobe; subsequent learning leads instead to major activation in the left motor cortex, left SMA, and pulvinar thalamus [Grafton et al., 1992, 1994; Hatakenaka, Miyai, Mihara, Sakoda, \& Kubota, 2007]. Although no study to date has investigated brain activation during the PR tasks in children with ASD, a first fMRI study by Mostofsky, Powell, Simmonds, Goldberg, Caffo, and Pekar [2009] highlighted reduced activation in the cerebellum and greater activation in the SMA in a group of children with ASD performing a finger-sequencing task compared to TD controls. It may be that abnormalities in these areas contribute to differences in PR execution and procedural learning in children with ASD, however, further studies are needed to better understand the relation between behavioral data and neurophysiological evidence.

Overall, the VPR proved to be economical (i.e., depending on low-cost and popular hardware resources and on open-access software), portable (i.e., usable within minimally structured settings), and user-friendly (i.e., requiring minimal training). Therefore, the VPR task, may hopefully be used in future studies, promoting further research on procedural learning and motor strategies in ASD as well as other developmental disorders, potentially supporting future cross-syndrome comparisons.

\section{Acknowledgments}

The work reported in this article was supported by: MIUR-FIRB TOUM project (no. RBFR086HEW) to L.S. and D.F. and Fondazione Handicap Dopodinoi, Onlus to S.V. The authors are very grateful to the primary school Istituto Comprensivo "Piazza Borgoncini Duca" in Rome for participating in this study. The authors wish to thank Dr Patrizio Pasqualetti and Dr Pasquale Rinaldi for their help with statistical analyses. In particular, the authors wish to thank all the children and families who have participated in this research.

\section{References}

Ammons, R.B., Alprin, S.I., \& Ammons, C.H. (1955). Rotary pursuit performance as related to sex and age of pre-adult subjects. Journal of Experimental Psychology, 49, 127-133.
Beery, K., \& Beery, N. (2004). The developmental test of visual motor integration. Los Angeles, CA: Western Psychological Services.

Bhat, A.N., Landa, R.J., \& Galloway, J.C. (2011). Current perspectives on motor functioning in infants, children, and adults with autism spectrum disorders. Physical Therapy, 91, 1116-1129.

Brown, J., Aczel, B., Jimenez, L., Kaufman, S. B., \& Grant, K. P. (2010). Intact implicit learning in autism spectrum conditions. The Quarterly Journal of Experimental Psychology (Colchester.), 63, 1789-1812.

Capirci, O., \& Volterra, V. (2008). Gesture and speech. The emergence and development of a strong and changing partnership. Gesture, 8, 22-44.

Cattaneo, L., Fabri-Destro, M., Boria, S., Pieraccini, C., Monti, A., Cossu G., et al. (2007). Impairment of actions chains in autism and its possible role in intention understanding. Proceedings of the National Academy of Sciences of the United States of America, 104, 17825-17830.

Cohen, N.J., \& Poldrack, R.A. (1997). Memory for items and memory for relations in the procedural/declarative memory framework. Memory, 5, 131-178.

Cornhill, H., \& Case-Smith, J. (1996). Factors that relate to good and poor handwriting. American Journal of Occupational Therapy, 50, 732-739.

Davol, S.H., \& Breakell, S.L. (1965). Effect of age, sex, and speed of rotation on rotary pursuit performance by young children. Perceptual and Motor Skills, 21, 351-357.

Dickerson Mayes, S., \& Calhoun, S.L. (2003a). Ability profiles in children with autism: Influence of age and IQ. Autism, 7, 65-80.

Dickerson Mayes, S., \& Calhoun, S.L. (2003b). Analysis of WISC-III, Stanford-Binet: IV, and academic achievement test scores in children with autism. Journal of Autism and Developmental Disorders, 33, 329-341.

Dickerson Mayes, S., \& Calhoun, S.L. (2007). Learning, attention, writing, and processing speed in typical children and children with ADHD, autism, anxiety, depression, and oppositional-defiant disorder. Child Neuropsychology, 13, 469-493.

Dunham, P., Allan, R., \& Winter, R. (1985). Tracking ability of elementary school-age children. Perceptual and Motor Skills, 60, 771-774.

Dunn, L. M., \& Dunn, L. (1981). Peabody picture vocabulary test revised (PPVT-R). Circle Pines, MN: American Guidance Service.

Dziuk, M.A., Gidley Larson, J.C., Apostu, A., Mahone, E.M., Denckla, M.B., \& Mostofsky, S.H. (2007). Dyspraxia in autism: Association with motor, social, and communicative deficits. Developmental Medicine and Child Neurology, 49, 734-739.

Eckert, H.M. (1974). Variability in skill acquisition. Child Development, 45, 487-489.

Fabbri-Destro, M., Cattaneo, L., Boria, S., \& Rizzolatti, G. (2009). Planning actions in autism. Experimental Brain Research, 192, 521-525.

Forti, S., Valli, A., Pergo, P., Nobile, M., Crippa, A., \& Molteni, A. (2011). Motor planning and control in autism. A kinematic analysis of preschool children. Research in Autism Spectrum Disorders, 5, 834-842. 
Foti, F., De Crescenzo, F., Vivanti, G., Menghini, D., \& Vicari, S. (2014). Implicit learning in individuals with autism spectrum disorders: A meta-analysis, Psychological Medicine, $15,1-14$.

Fournier, K.A., Hass, C.J., Naik, S.K., Lodha, N., \& Cauraugh, J.H. (2010). Motor coordination in autism spectrum disorders: A synthesis and meta-analysis. Journal of Autism and Developmental Disorders, 40, 1227-1240.

Frith, C.D. (1968). Strategies in rotary pursuit tracking and their relation to inhibition and personality. Life Sciences, 7, 65-76.

Frith, C.D. (1971). Strategies in rotary pursuit tracking. British Journal of Psychology, 62, 187-197.

Frith, C.D. (1973). Learning rhythmic hand movements. Quarterly Journal of Experimental Psychology, 25, 253-259.

Frith, U., \& Frith, C.D. (1974). Specific motor disabilities in Down syndrome. Journal of Child Psychology and Psychiatry, $15,293-301$.

Fuentes, C.T., Mostofsky, S.H., \& Bastian, A.J. (2009). Children with autism show specific handwriting impairments. Neurology, 73(19), 1532-1537.

Gabay, Y., Schiff, R., \& Vakil, E. (2012). Dissociation between the procedural learning of letter names and motor sequences in developmental dyslexia. Neuropsychologia, 50, 24352441.

Gidley Larson, J.-C., \& Mostofsky, S.H. (2008). Evidence that the pattern of visuomotor sequence learning is altered in children with autism. Autism Research, 1, 341-353.

Gidley Larson, J.-C., Bastian, A.J., Donchin, O., Shadmehr, R., \& Mostofsky, S.H. (2008). Acquisition of internal models of motor tasks in children with autism. Brain, 131, 28942903.

Gowen, E., \& Hamilton, A. (2013). Motor abilities in autism: A review using a computational context. Journal of Autism and Developmental Disorders, 43, 323-344.

Grafton, S.T., Mazziotta, J.C., Presty, S., Friston, K.J., Franckowiak, R.S.J., \& Phelpsis, M.E. (1992). Functional anatomy of human procedural learning determined with regional cerebral blood flow and PET. Journal of Neuroscience, 12, 2542-2548.

Grafton, S.T., Woods, R.P., \& Tyska, M. (1994). Functional imaging of procedural motor learning: Relating cerebral blood flow with individual subject performance. Human Brain Mapping, 1, 221-234.

Harrington, D., Haaland, K.Y., Yoe, R.A., \& Marder, E. (1990). Procedural memory in Parkinson's disease: Impaired motor but not visuoperceptual learning. Journal of Clinical and Experimental Neuropsychology, 12, 323-339.

Haswell, C.C., Izawa, J., Dowell, L.R., Mostofsky, S.H., \& Shadmehr, R. (2009). Representation of internal models of action in the autistic brain. Nature Neuroscience, 12, 970 972.

Hatakenaka, M., Miyai, I., Mihara, M., Sakoda, S., \& Kubota, K. (2007). Frontal regions involved in learning of motor skill A functional NIRS study. NeuroImage, 34, 109-116.

Hatakenaka, M., Miyai, I., Mihara, M., Yagura, H., \& Hattori, N. (2012). Impaired motor learning by a pursuit rotor test reduces functional outcomes during rehabilitation of poststroke ataxia. Neurorehabilitation and Neural Repair, 26, 293-300.
Horn, P.W. (1975). Pursuit rotor speed, sex differences, and reminiscence in young children. The Journal of Psychology: Interdisciplinary and Applied, 91, 81-85.

Hsu, H.J., \& Bishop, D.V.M. (2014). Sequence-specific procedural learning deficits in children with specific language impairment. Developmental Science, 17, 352-365.

Hughes, C. (1996). Brief report: Planning problems in autism at the level of motor control. Journal of Autism and Developmental Disorders, 26, 99-107.

Iverson, J.M., \& Wozniak, R. (2007). Variation in vocal-motor development in infant siblings of children with autism. Journal for Autism and Developmental Disorders, 37, 158170.

Izawa, J., Pekny, S.E., Marko, M.K., Haswell, C.C., Shadmehr, R., \& Mostofsky, S.H. (2012). Motor learning relies on integrated sensory inputs in ADHD, but over-selectivity on proprioception in autism spectrum conditions. Autism Research, 5, 124-136.

Karlin, L. (1965). Effects of delay and mode of presentation of extra cues on pursuit-rotor performance. Journal of Experimental Psychology, 4, 438-440.

Klein, S., Guiltner, V., Sollereder, P., \& Cui, Y. (2011). Relationships between fine-motor, visual-motor, and visual perception scores and handwriting legibility and speed. Physical \& Occupational Therapy in Pediatrics, 31, 103-114.

Kushki, A., Chau, T., \& Anagnostou, E. (2011). Handwriting difficulties in children with autism spectrum disorders: A scoping review. Journal of Autism and Developmental Disorders, $41,1706-1716$.

Leonard, H.C., Bedford, R., Charman, T., Elsabbagh, M., Johnson, M.K., Hill, E.L., et al. (2014). Motor development in children at risk of autism: A follow-up study of infant siblings. Autism, 18, 281-291.

Lord, R., \& Hulme, C. (1988). Patterns of rotary pursuit performance in clumsy and normal children. Journal of Child Psychology and Psychiatry, 29, 691-701.

Lord, C., Risi, S., Lambrecht, L., Cook, E.H. Jr., Leventhal, B.L., DiLavore, P.C., et al. 2000. The autism diagnostic observation schedule - Generic: A standard measure of social and communication deficits associated with the spectrum of autism. Journal of Autism and Developmental Disorders, 30(3), 205-223.

Lord, C., Rutter, M., Di Lovore, P.C., \& Risi, S. (2005). Autism diagnostic observation schedule. Florence, Italy: Organizzazioni Speciali.

Masterton, B.A., \& Biederman, G.B. (1983). Proprioceptive versus visual control in autistic children. Journal of Autism and Developmental Disorders, 13, 141-152.

McCleery, J.P., Elliott, N.A., Sampanis, D.S., \& Stefanidou, C.A. (2013). Motor development and motor resonance difficulties in autism: relevance to early intervention for language and communication skills, Frontiers in Integrative Neuroscience, 7, 1-20.

Mostofsky, S.H., Powell, S.K., Simmonds, D.J., Goldberg, M.C., Caffo, B., \& Pekar, J.J. (2009). Decreased connectivity and cerebellar activity in autism during motor task performance. Brain, 132, 2413-2425.

Mostofsky, S.H. \& Ewen, J.B. (2011). Altered connectivity and action model formation in autism is autism. The Neuroscientist, $17,437-448$. 
Mounoud, P., Viviani, P., Hauert, C.A., \& Guyon, J. (1985). Development of visuomanual tracking in 5- to 9-year-old boys. Journal of Experimental Child Psychology, 40, 115132.

Mueller, S.T. (2012). The psychology experiment building language, version 0.13. pebl.sourceforge.net. Retrieved July 23, 2014, from http://pebl.sourceforge.net/download.html.

Neiner, R.A. (1971). Visual perceptual development and performance on eye-hand coordination tasks in first and thirdgrade children. Unpublished Master's Thesis. Berkely: University of California.

Nemeth, D., Janacsek, K., Balogh, V., Londe, Z., Mingesz, R., Fazekas, M., et al. (2010). Learning in autism: Implicitly superb. PloSOne, 5, e11731.

Okamoto, E. (1964). Personality trait deduced from behavior: Theory I. Mirror drawing measures on the vertivity axis. Japanese Psychological Research, 6, 99-107.

Piper, B.J. (2011). Age, handedness, and sex contribute to fine motor behavior in children. Journal of Neuroscience Methods, 195, 88-91.

Raven, J.C., Court, J.H., \& Raven, J. (1990). Coloured progressive matrices. Oxford: Oxford Psychologists Press.

Rosenbaum, D.A. (2010). Human motor control (2nd ed.). San Diego, CA: Academic Press/Elsevier.

Sarazin, M., Deweer, B., Merkl, A., Poser, N.V., Pillon, B., \& Dubois, B. (2002). Procedural learning and striatofrontal dysfunction in Parkinson's Disease. Movement Disorders, 17, 265-273.

Schmidtke, K., Manner, H., Kaufmann, R., \& Schmolck, H. (2002). Cognitive procedural learning in patients with fronto-striatal lesions. Learning and Memory, 9, 419-429.

Sparaci, L., Stefanini, S., D’Elia, L., Vicari, S., \& Rizzolatti, G. (2014). What and Why understanding in Autism Spectrum Disorders and Williams Syndrome: similarities and differences. Autism Research, 7, 421-432.

Squire, L. (1986). Mechanisms of memory. American Association for Advancement of Science, 232, 1612-1619.

Stella, G., Pizzoli, C., \& Tressoldi, P.E. (2000). Peabody. Test di Vocabolario Ricettivo. Torino: Omega Edizioni.

Tseng, M., \& Cermak, S. (1993). The influence of ergonomic factors and perceptual-motor abilities on handwriting performance. American Journal of Occupational Therapy, 47, 919-926.

Ullman, M.T. (2004) Contributions of memory circuits to language: The declarative/procedural model. Cognition, 92, 231270.
Van Roon, D., Caeyenberghs, K., Swinnen, S.P., \& SmitsEngelsman, B.C. (2008). Development of feedforward control on a dynamic manual tracking task. Child Development, 79, 852-865.

Vicari, S., Marota, L., \& Luci, A. (2007). TFL-Test Fono Lessicale. Valutazione delle abilità lessicali in età prescolare [TFL_Phono-Lexical Test. Assessment of Lexical Abilities in Preschool Children]. Trento: Centro Studi Erickson.

Vicari, S., Verucci, L., \& Carlesimo, G.A. (2007). Implicit memory is independent from IQ and age but not from etiology: Evidence from Down and Williams syndromes. Journal of Intellectual Disability Research, 51, 932-941.

Vivanti, G., McComick, C., Young, G.S., Abucayan, F., Hatt, N., Nadig, A., et al. (2011). Intact and impaired mechanisms of action understanding in autism. Developmental Psychology, 47, 841-856.

Volman, M.J.M., van Schendel, B.M., \& Jongmans, M.J. (2006). Handwriting difficulties in primary school children: A search for the underlying mechanisms. The American Journal of Occupational Therapy, 60, 451-460.

Von Hofsten, C., \& Rosander, K. (1997). Development of smooth pursuit tracking in young infants. Vision Research, 37, 1799-1810.

Von Hofsten, C., \& Rosander, K., (2012). Perception-action in children with ASD. Frontiers in Integrative Neuroscience, 6, 115.

Watanabe, K., Ikeda, H., \& Miyao, M. (2010). Learning efficacy of explicit visuomotor sequences in children with attention-deficit/hyperactivity disorder and Asperger syndrome. Journal of Experimental Brain Research, 203, 233-239.

Wechsler, D. (1991). WISC-III: Wechsler intelligence scale for children. New York: The Psychological Corporation.

Wechsler, D. (2003). Wechsler intelligence scale for children (4th ed.). San Antonio, TX: Psychological Corporation.

Weintraub, N., \& Graham, S. (2000). The contribution of gender, orthographic, finger function, and visual-motor processes to the prediction of handwriting status. Occupational Therapy Journal of Research, 20, 121-140.

Wek, S.R., \& Husal, W.S. (1989). Distributed and massed practice effects on motor performance and learning of autistic children. Perceptual and Motor Skills, 68, 107-113.

Whitehurst, M., \& Del Rey, P., (1983). Effects of contextual interference, task difficulty and levels of processing on pursuit tracking. Perceptual and Motor Skills, 57, 619-628.

Zanone, P.G. (1990). Tracking with and without target in 6-to 15-year-old boys. Journal of Motor Behavior, 22, 225-249. 